\title{
Astrocytes Control Synapse Formation, Function, and Elimination
}

\author{
Won-Suk Chung ${ }^{1}$, Nicola J. Allen ${ }^{2}$, and Cagla Eroglu ${ }^{3}$ \\ ${ }^{1}$ Stanford University, School of Medicine, Department of Neurobiology, Stanford, California 94305 \\ ${ }^{2}$ Salk Institute for Biological Studies, Molecular Neurobiology Laboratory, La Jolla, California 92037 \\ ${ }^{3}$ Duke University Medical Center, Cell Biology and Neurobiology Departments, Duke Institute for Brain \\ Sciences, Durham, North Carolina 27710 \\ Correspondence: cagla.eroglu@dm.duke.edu
}

\begin{abstract}
Astrocytes, through their close associations with synapses, can monitor and alter synaptic function, thus actively controlling synaptic transmission in the adult brain. Besides their important role at adult synapses, in the last three decades a number of critical findings have highlighted the importance of astrocytes in the establishment of synaptic connectivity in the developing brain. In this article, we will review the key findings on astrocytic control of synapse formation, function, and elimination. First, we will summarize our current structural and functional understanding of astrocytes at the synapse. Then, we will discuss the cellular and molecular mechanisms through which developing and mature astrocytes instruct the formation, maturation, and refinement of synapses. Our aim is to provide an overview of astrocytes as important players in the establishment of a functional nervous system.
\end{abstract}

In the central nervous system (CNS), astrocytes are closely associated with synapses. Through this association, astrocytes can monitor and alter synaptic function, thus actively controlling synaptic transmission. This close structural and functional partnership of the perisynaptic astrocytic process with the neuronal pre- and postsynaptic structures led to the "tripartite synapse" concept (Araque et al. 1999). Besides their important role at adult synapses, in the last three decades a number of critical findings highlighted the importance of astrocytes in the establishment of synaptic connectivity in the CNS. These discoveries fundamentally changed the way we view astrocytes and led to the birth of a now thriving area of cellular neuroscience.

Our aim here is to provide the current understanding of astrocytes as active participants in the construction of synaptic circuits. In this article, we will review the key findings on astrocytic control of synapse formation, function, and elimination. We will start by evaluating our structural and functional understanding of astrocytes at the synapse. We will then discuss, in detail, the molecular mechanisms through which developing and mature astrocytes instruct the formation, maturation, and refinement of synapses. Along the way, we will also highlight the important gaps in our knowl-

Editors: Ben A. Barres, Marc R. Freeman, and Beth Stevens

Additional Perspectives on Glia available at www.cshperspectives.org

Copyright (C) 2015 Cold Spring Harbor Laboratory Press; all rights reserved; doi: 10.1101/cshperspect.a020370

Cite this article as Cold Spring Harb Perspect Biol 2015;7:a020370 
W.-S. Chung et al.

edge that remain to be addressed by future research.

\section{PROPERTIES OF ASTROCYTES AT SYNAPSES}

Astrocyte Processes Ensheath Synapses and Define Functional Domains

Astrocytes closely interact with surrounding structures in the nervous system and contribute to the regulation of their functions. For example, astrocyte processes contribute to the glia limitans of the neural tube, and astrocyte endfeet contact blood vessels and control blood flow. Astrocytes also tightly ensheath neuronal somas, axons, dendrites, and synapses (Fig. 1).
Astrocytes occupy nonoverlapping territories, and these domains are established through a developmental process (Bushong et al. 2002; Ogata and Kosaka 2002; Halassa et al. 2007). During the first postnatal week, astrocyte processes are initially intermingled and then, during the second postnatal week, gradually establish independent domains. This process of segregation, also known as astrocyte tiling, is thought to be regulated by "contact inhibition" between neighboring astrocytes (Distler et al. 1991). However, the functional significance of this phenomenon and the molecular mechanisms that control this process are largely unknown. Astrocyte tiling may be crucial for normal functions of the nervous system because, in
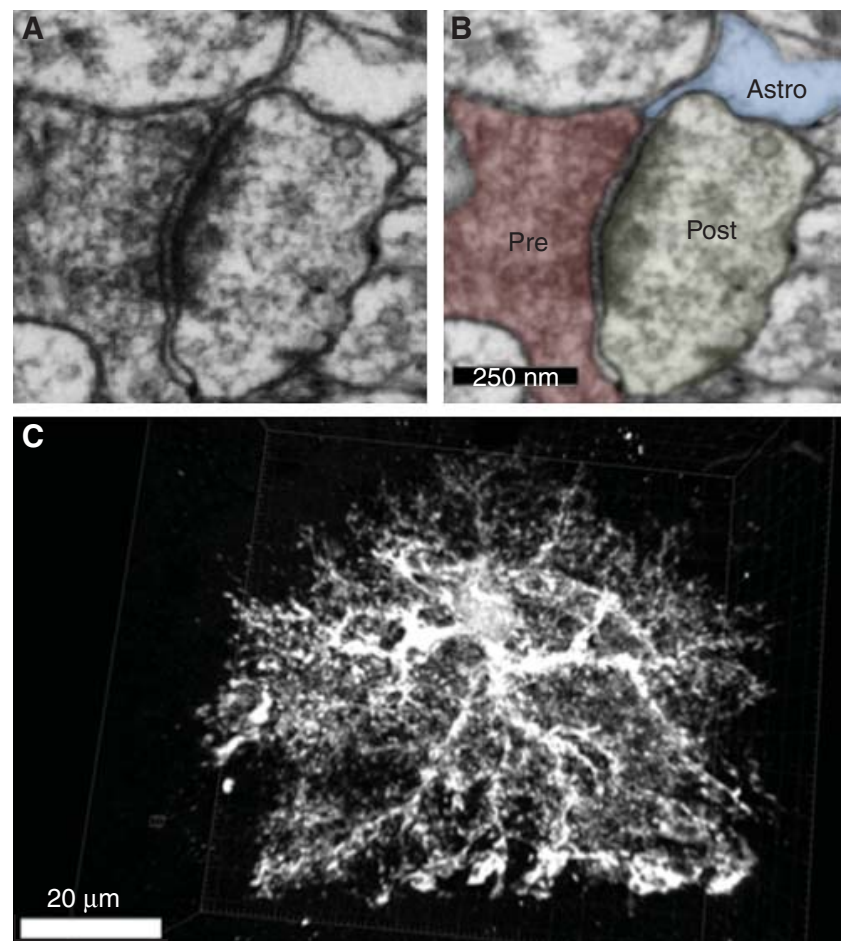

Figure 1. Astrocytic processes contact synapses. (A) Electron micrograph of a tripartite synapse in the mouse visual cortex. (B) The micrograph in $A$ is highlighted to show an astrocyte process (blue) contacting both preand postsynaptic neural structures (red and green, respectively). Scale bar, $250 \mathrm{~nm}$. (C) Three-dimensional reconstruction of an enhanced green fluorescent protein (EGFP)-labeled astrocyte from the 18-d-old mouse cortex reveals the complexity of astrocyte morphology. The astrocyte is comprised of several projections emanating from a central soma, which ramify to create hundreds of fine branches. These branches terminate at neuronal synapses to regulate synaptic formation and/or function or envelop blood vessels to help maintain the blood-brain barrier. Scale bar, $20 \mu \mathrm{m}$. (Images are the courtesy of Jeff A. Stogsdill, Eroglu Laboratory, Duke University Medical Center.) 
disease and postinjury conditions, astrocytes lose their tiling and display intermingled process morphology (Oberheim et al. 2009).

Detailed quantification of astrocyte domains in mice revealed that one cortical astrocyte enwraps multiple neuronal cell bodies and up to 600 dendrites and, through the finer processes, one astrocyte contacts $\sim 100,000$ synapses (Halassa et al. 2007). The complex of astrocyte processes with presynaptic and postsynaptic structures form the tripartite synapse (Araque et al. 1999). The tight structural interactions between synapses and astrocytes have important functional consequences. Astrocyte processes contain neurotransmitter receptors, transporters, and cell-adhesion molecules that mediate synapse-astrocyte communication. Because of this structural arrangement, astrocytes can monitor synaptic activity and, in turn, control synaptic transmission within a functional island of synapses, that is, a group of synapses confined within the boundaries of an individual astrocyte (Halassa et al. 2007). The functional consequences of the synaptic islands defined by astrocytes remain to be determined, but it is possible that an astrocyte provides an additional level of connectivity among synapses that are within its domain via signaling through the astrocyte.

\section{Astrocyte Processes Segregate Neighboring Synapses}

One of the most important functions of astrocytes at the synapse is the clearance of neurotransmitters. For example, the astrocytic processes that are associated with excitatory synapses are covered with glutamate transporters, which maintain a low ambient level of glutamate in the CNS and shape the activation of glutamate receptors at synapses. Astrocytic processes may have a specific attraction toward postsynaptic sites. Occurrence of astrocyte processes was found to be three- to fourfold higher at the postsynapse compared with the presynapse (Lehre and Rusakov 2002). Caused by this asymmetric localization of astrocytes at excitatory synapses, the glutamate escaping the synaptic cleft is $2-4$ times more likely to activate glutamate receptors that are at the periphery of the presynaptic side compared with the extrasynaptic receptors at the spines. This asymmetry is even more exaggerated in the cerebellum in which Bergman glia ensheath a vast majority of Purkinje cell spines (Grosche et al. 1999). These observations suggest that astrocyte-synapse interactions favor fast presynaptic feedback because of glutamate overflow, while preserving the specificity of postsynaptic transmission (Rusakov and Lehre 2002). Interestingly, the extent of astrocyte ensheathment differs among brain regions (e.g., $74 \%$ of the cerebellar Purkinje cell synapses are ensheathed by astrocytes as opposed to $29 \%$ of the dendritic spines in the mouse visual cortex) (Spacek 1985; Ventura and Harris 1999). Moreover, astrocyte-synapse interactions are also regulated by physiological states of animals (e.g., hydrated vs. dehydrated rats or oxygen/glucose deprivation) and can be manipulated by experience (e.g., environmental enrichment or whisker stimulation) (Wittkowski and Brinkmann 1974; Jones and Greenough 1996; Genoud et al. 2006). These observations suggest that astrocyte-synapse interactions are dynamically regulated, and the extent of interactions between astrocytes and synapses may determine synaptic characteristics.

\section{Astrocyte-Synapse Interactions Are Dynamic}

Time-lapse imaging of astrocytes and dendrites in organotypic slices from different brain regions show the dynamic nature of fine astrocytic processes, as they rapidly extend and retract to engage and disengage from postsynaptic dendritic spines. In the brain stem, astrocyte processes interact with neuronal dendrites and spines through at least two distinct microstructures: flat lamellipodia-like astrocyte processes, and the more transient filopodia-like astrocytic protrusions (Grass et al. 2004). Similarly, astrocytic processes actively interact with neuronal dendrites and spines in the mouse hippocampus (Murai et al. 2003; Haber et al. 2006). In the hippocampus, dendritic spines are well known to rapidly undergo structural changes, and these changes are linked to synaptic events, such as 
W.-S. Chung et al.

long-term potentiation (LTP) and long-term depression (LTD) (Murakoshi and Yasuda 2012). Akin to spines, astrocytic processes also undergo significant and rapid changes in volume and motility. Importantly, the changes in astrocytic microstructures are independently regulated when neighboring processes from the same astrocyte are compared, indicating a local regulation of astrocytic process dynamics at the tripartite synapse (Haber et al. 2006). Astrocyte-spine interactions are stabilized at larger spines, suggesting that stronger synapses recruit stable astrocytic contacts (Haber et al. 2006).

Our current molecular knowledge on how astrocyte-synapse interactions are mediated is limited; however, a contact-mediated mechanism involving bidirectional ephrin/EphA signaling was previously described (Murai et al. 2003). In the hippocampus, astrocytes and their processes express ephrin A3, whereas neurons express the ephrin receptor EphA4. Perturbing ephrin/EphA signaling either by delivering soluble ephrin A3 in hippocampal slice cultures or by transfecting neurons with a kinase inactive EphA4 results in defects in spine formation and maturation. Similarly, mice lacking ephA4 or ephrin-3A have aberrant spine morphology (Carmona et al. 2009; Filosa et al. 2009). It is possible that activity-dependent mechanisms that regulate ephrin/EphA signaling can modulate astrocyte-synapse interactions, thus controlling synaptic stability and potentially also synapse elimination and refinement.

In summary, astrocyte processes closely interact with neuronal synapses throughout life, and this interaction is highly dynamic, enabling ongoing modulation of synaptic function by astrocytes.

\section{REQUIREMENT OF GLIA/ASTROCYTES FOR SYNAPSE FORMATION AND FUNCTION}

In the rodent cerebral cortex, the majority of neuronal cells mature and project axons to their targets within a few days after birth; however, by the end of the first postnatal week, few synapses have been formed. The majority of excitatory synaptic structures in the rodent brain appear during the second and third postnatal weeks. This period of extensive synapse formation coincides with the differentiation and maturation of astrocytes. These observations indicated that astrocytes may contribute to the timing and extent of synapse formation in the CNS. However, this was difficult to test because astrocytes are crucial for the survival and health of neurons, both in culture and in vivo (Banker 1980). In the mouse cortex, deletion of Mek1 and Mek2 in radial glia eliminates astrocyte and oligodendrocyte precursors, thus obliterating gliogenesis (Li et al. 2012b). These glia-free mice are born, but the majority of them cannot survive past the first 2 postnatal weeks as a result of extensive neurodegeneration, which occurs in the absence of glia. Similarly, in the peripheral nervous system (PNS), ablation of perisynaptic Schwann cells, which have analogous roles in the PNS to astrocytes in the CNS, leads to loss of normal synaptic transmission and causes degeneration and loss of neuromuscular junctions (NMJs) (Reddy et al. 2003).

Traditional neuronal culture systems, such as those that use embryonic hippocampal and cortical neurons, require astrocytes for correct neuronal differentiation and survival (Banker 1980). This major bottleneck for studying the role of astrocytes in synapse formation was overcome by the use of purified cultures of retinal ganglion cell (RGC) neurons (Meyer-Franke et al. 1995). These neurons can be isolated from postnatal rodent retinas by using antibodies specific for surface antigens on RGCs and can be cultured in the presence of known survival factors in a serum-free media, which supports their long-term survival and health. Interestingly, under these conditions, RGCs grow out neurites and contact each other, but they make very few synapses. On the contrary, if these RGCs are cultured in the presence of astrocyte feeder layers or fed by culture media that is previously conditioned by astrocytes (i.e., astrocyte conditioned media [ACM]), then RGCs establish many synapses (Fig. 2). Using this system, it was discovered that astrocytes control different stages of excitatory synapse formation (Fig. 3) via different secreted factors: (1) astrocytes increase the number of synaptic structures, (2) 


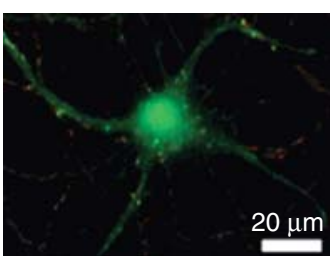

Growth media alone

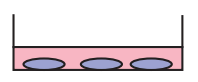

RGCs
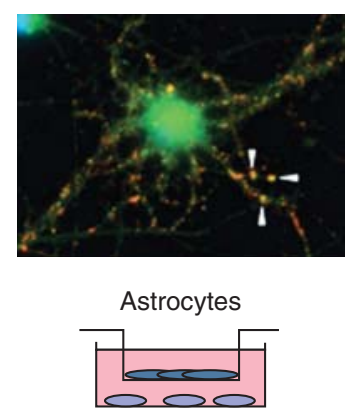

RGCs
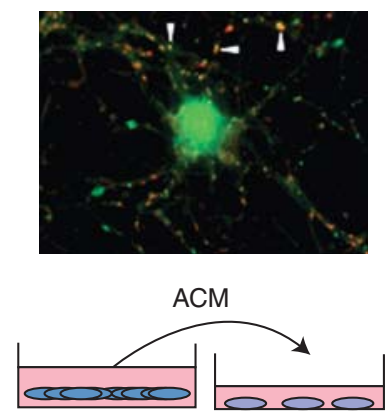

Astrocytes

RGCs

Figure 2. Retinal ganglion cells (RGCs) can be purified by sequential immunopanning to $>99.5 \%$ purity from P7 Sprague-Dawley rats and cultured in a neurobasal medium-based growth media that contains several neurotrophic factors, such as brain-derived neurotrophic factor (BDNF) and ciliary neurotrophic factor (CNTF). RCGs are cultured for 3-4 d to allow robust process outgrowth and then cultured for 6 additional $\mathrm{d}$ with growth media or astrocyte feeder inserts or with astrocyte-conditioned media (ACM). Change in synapse number in response to treatments is assayed by staining these neurons with antibodies against a pre- and a postsynaptic protein (bassoon, red; homer-1, green). Pre- and postsynaptic proteins appear colocalized (arrowheads) at the synapse because of their close proximity. Astrocytes and ACM strongly increase the number of colocalized synaptic puncta. (Images are courtesy of Sehwon Koh, Eroglu Laboratory, Duke University Medical Center.)

astrocytes increase postsynaptic activity by inducing AMPA receptor localization to the postsynaptic density, and (3) astrocytes enhance presynaptic function by increasing release probabilities.

The RGC culture system provided a platform to identify astrocyte-secreted factors that control these different aspects of synapse formation and functional maturation, which will be discussed in the following sections.

\section{ASTROCYTE-SECRETED FACTORS CONTROL STRUCTURAL SYNAPSE FORMATION AND MATURATION}

Thrombospondins Are Major Contributors to Astrocyte-Regulated Synapse Formation

As outlined in the previous section, astrocytes secrete factors that greatly increase the number of structural synapses that neurons form. The first family of proteins that was identified to be a major synaptogenic factor secreted by astrocytes and present in ACM was the extracellular matrix (ECM) proteins, thrombospondins (TSPs) (Christopherson et al. 2005). There are five TSPs in mammals. Protoplasmic gray- matter astrocytes express TSP1 and -2, whereas astrocytes originating from the subventricular zone and fibrous white matter astrocytes express TSP4 (Eroglu 2009; Benner et al. 2013). Addition of purified TSP protein to cultured neurons increased the synapse number to levels comparable to ACM. Removal of TSPs from ACM eliminated the majority of the synaptogenic activity of ACM. In agreement with these in vitro findings, TSP $1 / 2$ double knockout (KO) mice displayed fewer cortical excitatory synapses, indicating that TSPs are important for synapse development in vivo. Interestingly, in the rodent cortex, TSPs are expressed by immature astrocytes only during the first week of postnatal development, a time period that corresponds to the initiation of excitatory synapse formation in this region (Christopherson et al. 2005). In adult mice, the levels of TSPs are low, but TSP levels are greatly increased after injury. Lack of TSPs leads to defects in injury-induced structural plasticity of the developing barrel cortex (Eroglu et al. 2009) and hampers synaptic recovery after stroke, showing an important role for astrocyte-derived TSPs in regulating the formation of new synapses after injury (Liauw et al. 2008). 
W.-S. Chung et al.

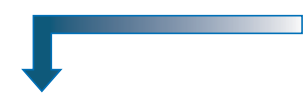

1. Silent "structural" synapses

TSPs $\uparrow$ SPARCL1/Hevin $\uparrow$ SPARC $\downarrow$

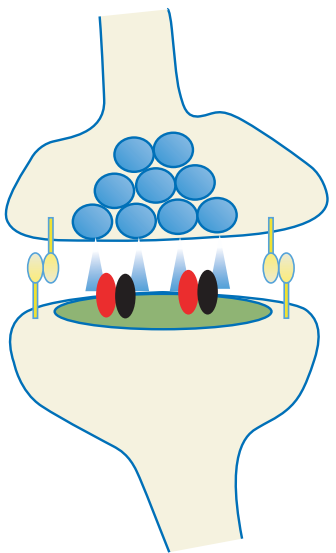

Astrocytes

2. Postsynaptically active "functional " synapses

Glypicans 4/6 $\uparrow$

TSPs $\downarrow$

SPARC $\downarrow$

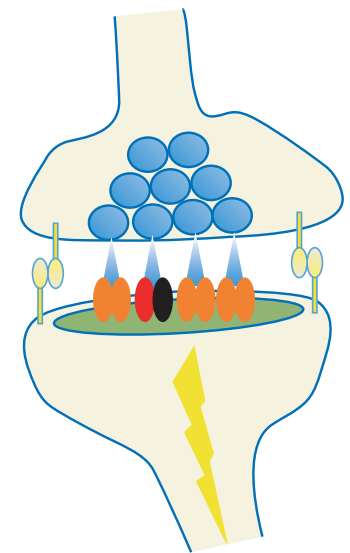

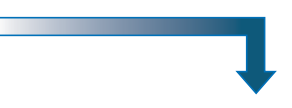

3. Presynaptic function ApoE/cholesterol $\uparrow$ TSPS $4 \mathrm{x}$ SPARC $\downarrow$

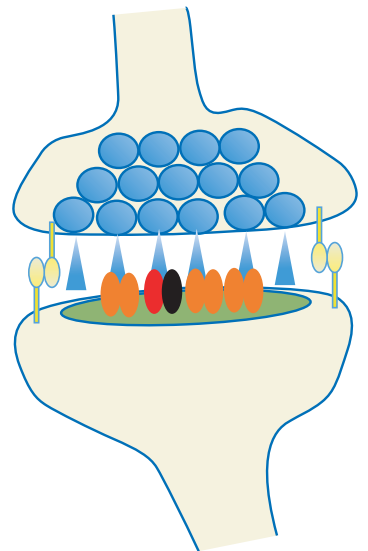

Figure 3. Astrocyte-secreted factors control different aspects of excitatory synaptic development. (1) Astrocytes increase the number of structural synapses. These synapses have normal morphology and contain $N$-methyl-Daspartate (NMDA) receptors (red and black). However, they lack AMPA-type glutamate receptors (orange). (2) Astrocytes increase postsynaptic activity by inducing AMPA receptor localization to the postsynaptic density.

(3) Astrocytes enhance presynaptic release by increasing release probabilities.

The calcium channel subunit $\alpha 2 \delta 1$ (Cacna $2 \mathrm{~d} 1$ ) was identified as the major synaptogenic neuronal receptor for TSPs (Eroglu et al. 2009). All five mammalian TSPs share the ability to induce synapse formation by binding via their type 2 EGF-like repeats to the von Willebrand factor A (VWFA) domain of neuronal Cacna2d1. Besides Cacna2d-1, TSPs also interact with a number of other cell-surface receptors and mediate other functions in the CNS (Risher and Eroglu 2012). TSP1 was also found to interact with the postsynaptic adhesion protein neuroligin 1 and, in this way, accelerate excitatory synapse formation in cultured hippocampal neurons (Xu et al. 2009a).

Interestingly, TSP receptor Cacna2d-1 is also the receptor for two commonly used drugs called Gabapentin (Neurontin) and Pregabalin (Lyrica). These drugs are used to treat neuropathic pain and epilepsy through an unknown mechanism of action. Treatment of RGCs with
Gabapentin and TSP completely abolished TSPinduced excitatory synaptogenesis in vitro. Gabapentin also profoundly inhibited excitatory synapse formation between neurons in the developing brain. Gabapentin prevents excitatory synapse formation by blocking the ability of TSP to bind its receptor Cacna2d1, thus inhibiting the synaptogenic signaling initiated by TSP-Cacna2d-1 interaction without affecting previously formed synapses (Eroglu et al. 2009). These findings provide an additional line of evidence highlighting the important ability of astrocytes to powerfully promote synapse formation in vivo. They also indicate that TSPCacna2d-1 signaling and astrocyte-induced synapse formation might be involved in the pathophysiology of diseases, such as neuropathic pain and epilepsy, for which gabapentin is a common treatment. In fact, under injury or seizure conditions that lead to establishment of neuropathic pain or epilepsy, expression of 
Synapse Formation, Function, and Elimination

TSPs and Cacna2d1 are highly up-regulated. Inhibition of TSP or Cacna2d1 up-regulation, or blocking of their interaction by gabapentin, blocked establishment of pain states and prevented epileptogenic activity (Boroujerdi et al. 2011; Kim et al. 2012; Li et al. 2012a).

\section{Role of SPARC Family Proteins in Synapse Formation}

A secreted protein acidic, rich in cysteine (SPARC) family protein, hevin (also known as SPARC-like 1), was recently identified as another synaptogenic protein secreted by astrocytes (Kucukdereli et al. 2011). Hevin is highly expressed by developing and mature astrocytes in the brain and has been shown to localize to synaptic clefts (Johnston et al. 1990; Lively and Brown 2008). Hevin alone induces an increase in structural synapses among cultured RGCs, similar to the levels induced by TSPs. However, hevin was not able to exert its full synaptogenic activity in vitro when it was present within the ACM. This observation led to the discovery of an astrocyte-secreted protein that inhibits hevin-induced structural synapse formation. Astrocytes express SPARC, a secreted protein highly homologous to hevin. Unlike hevin, SPARC is not synaptogenic. On the contrary, when RGCs were treated concurrently with hevin and SPARC, the synaptogenic function of hevin was antagonized by SPARC. SPARC's antagonism is specific to hevin because SPARC does not prevent TSP-induced synapse formation (Kucukdereli et al. 2011). These findings showed that astrocytes not only provide positive signals that stimulate synapse formation, but also provide negative cues to inhibit synaptogenesis. These opposing actions of hevin and SPARC can thereby control the rate and extent of synapse formation and maturation in the CNS. In agreement with this possibility, analyses of hevin null and SPARC null mice showed that lack of hevin significantly impaired the formation and maturation of synaptic connections in the superior colliculus, the in vivo targets of RGCs, whereas lack of SPARC led to accelerated formation of synapses in this region (Kucukdereli et al. 2011).

\section{Astrocytic Synaptogenic Cues Alter during Development}

Neurons also undergo a developmental switch to be able to respond to soluble synaptogenic signals from astrocytes, and this switch is induced by direct contact with astrocytes. Interestingly, when RGCs from 17-d-old embryos (E17 RGCs) are cultured together with postnatal RGCs in the presence of ACM, E17 RGCs fail to receive synapses from postnatal RGCs, whereas their axons could establish synapses onto postnatal RGCs. By E19, RGCs started responding to ACM (Barker et al. 2008). This switch in receptivity between E17 and E19 correlates with the appearance of astrocytes in the retina. Indeed, physical contact with astrocytes but not amacrine cells in culture was sufficient for E17 RGCs to become receptive to synaptogenic signals secreted from astrocytes. Contact by astrocytes causes the synaptic adhesion molecule neurexin to partition out of the dendrites where it is inhibitory to synapse formation (Barker et al. 2008). Similarly, in cultured hippocampal neurons, contact with astrocytes was found to be critical for the neuron's ability to form synapses (Hama et al. 2004). The full extent of the molecular interactions that mediate contact-dependent synaptogenic signaling between astrocytes and neurons is not yet clear. Integrin-mediated protein kinase $\mathrm{C}$ signaling was proposed to play a critical role in hippocampal neurons (Hama et al. 2004). In addition, homophilic astrocyte-neuron adhesions established by a family of cell-adhesion molecules, $\gamma$ protocadherins, were shown to be important for both excitatory and inhibitory synaptogenesis in the spinal cord (Garrett and Weiner 2009).

Taken together, these findings suggest that astrocytes play an important role in determining the correct timing of structural synapse formation, as neurons are unable to form synapses until they are physically contacted by an astrocyte. Why would astrocytes require multiple signals to control excitatory synapse formation? The answer to this question may lie in the developmental expression patterns of these proteins. TSPs are expressed by immature astrocytes during a narrow developmental window 
W.-S. Chung et al.

(circa P5), coinciding with the initiation of nascent synaptic contacts between dendrites and axons (Christopherson et al. 2005). Hevin and SPARC expression in vivo peaks during the second and third weeks of development (Kucukdereli et al. 2011), a period in which experiencedependent synaptic activity drives the maturation of some synapses and the elimination of weaker synapses. Interestingly, astrocytes continue to express hevin into adulthood; however, SPARC expression is greatly reduced in the adult CNS. Thus, it is possible that in vivo TSP initiates structural synapse formation, and hevin acts to stabilize synaptic connections and facilitate their maturation.

\section{ASTROCYTES REGULATE SYNAPTIC FUNCTION}

Some of the earliest evidence that astrocytes regulate synapse development and function came from electrophysiological studies of cultured rodent neurons, showing that the presence of astrocytes greatly enhance synaptic activity and the amplitude of responses to applied neurotransmitters, including glutamate and $\gamma$-aminobutyric acid (GABA) (Liu et al. 1996; Pfrieger and Barres 1997; Li et al. 1999; Ullian et al. 2001). These initial findings on retinal (RGC) and hippocampal neurons have been repeated in neurons from multiple different brain regions and classes, including glycinergic spinal cord neurons, spinal motor neurons, cerebellar Purkinje neurons, cortical subplate neurons, neurons derived from adult hippocampal stem cells, and at the neuromuscular junction (NMJ) (reviewed in Ko and Robitaille 2015) (Song et al. 2002; Ullian et al. 2004; Cuevas et al. 2005; Cao and Ko 2007; Feng and Ko 2008; McKellar and Shatz 2009; Buard et al. 2010). In addition to rodent neurons, astrocytes enhance synaptic function between cultured human neurons, and in vivo in Caenorhabditis elegans sensory neuron function (Hartley et al. 1999; Johnson et al. 2007; Bacaj et al. 2008; C. elegans reviewed in Shaham 2014). These findings from multiple neuron types and species provide compelling evidence that astrocytes provide essential signals to neurons that regulate synaptic function.
This section will review the progress that has been made in identifying the astrocyte signals that regulate synaptic function, and will focus on factors that regulate developmental synapse maturation and receptor trafficking (for a review of the effects of astrocyte gliotransmitters on synaptic plasticity in mature neural circuits, see Haydon and Nedergaard 2015).

Astrocytes use many different signals to control specific aspects of synapse function, including presynaptic function and postsynaptic receptor recruitment, using both positive and negative signals to finely tune synaptic strength (Fig. 3; Table 1). The strength of a presynaptic connection is controlled by a number of factors. These include release probability, which is the likelihood of neurotransmitter vesicles being released from the presynaptic terminal in response to an action potential, and quantal content, which reflects the number of vesicles that are released in response to an action potential. Postsynaptic strength is determined by the number of functional neurotransmitter receptors that are clustered at the postsynaptic density. Response size can vary depending on receptor number, receptor subunit composition, phosphorylation status of the receptor, and stability of receptors in the postsynaptic density. Analysis of individual synaptic events (miniature excitatory postsynaptic currents [mEPSCs]) is commonly used to determine postsynaptic strength, as mEPSCs reflect the response of one synapse to the release of one vesicle of saturating levels of neurotransmitter, so the size of the mEPSC is a reflection of the strength of the postsynaptic side.

\section{Presynaptic Function}

Astrocyte-secreted cholesterol, complexed with apolipoprotein E lipoparticles, was identified as a positive regulator of glutamatergic presynaptic function (Mauch et al. 2001). Cholesterol enhances both presynaptic release probability and quantal content, thus increasing the efficacy of synaptic transmission by making it more likely that neurotransmitter will be released in response to an action potential. The ability of cholesterol to enhance postsynaptic function 
Synapse Formation, Function, and Elimination

Table 1. Astrocytic factors that control different aspects of synaptic development

\begin{tabular}{|c|c|c|c|}
\hline Molecule & Action & Findings & References \\
\hline \multicolumn{4}{|c|}{ Structural synapse formation } \\
\hline Thrombospondin & Positive & $\begin{array}{l}\text { Induces glutamatergic synapse formation; } \\
\text { secreted by astrocytes }\end{array}$ & $\begin{array}{l}\text { Christopherson et al. 2005; } \\
\text { Eroglu et al. 2009; Xu et al. } \\
\text { 2009a; Garcia et al. 2010; } \\
\text { Hughes et al. } 2010\end{array}$ \\
\hline $\begin{array}{l}\text { Hevin } \\
\quad \text { (SPARC-like 1) }\end{array}$ & Positive & $\begin{array}{l}\text { Induces glutamatergic synapse formation; } \\
\text { secreted by astrocytes }\end{array}$ & Kucukdereli et al. 2011 \\
\hline$\gamma$-Protocadherins & Positive & $\begin{array}{l}\text { Induces glutamatergic and GABAergic } \\
\text { synapse formation; contact mediated }\end{array}$ & Garrett and Weiner 2009 \\
\hline BDNF & Positive & $\begin{array}{l}\text { Induces glutamatergic synapse formation; } \\
\text { secreted by vestibular support cells }\end{array}$ & Gómez-Casati et al. 2010 \\
\hline TGF- $\beta$ & Positive & $\begin{array}{l}\text { Induces glutamatergic synapse formation; } \\
\text { regulates synapse maturation }\end{array}$ & $\begin{array}{l}\text { Diniz et al. 2012; Fuentes- } \\
\text { Medel et al. } 2012\end{array}$ \\
\hline Estrogen & Positive & Induces glutamatergic synapse formation & Hu et al. 2007 \\
\hline SPARC & Negative & $\begin{array}{l}\text { Inhibits glutamatergic synapse formation; } \\
\text { antagonist of hevin }\end{array}$ & Kucukdereli et al. 2011 \\
\hline \multicolumn{4}{|c|}{ Presynaptic function } \\
\hline Cholesterol & Positive & $\begin{array}{l}\text { Increases presynaptic strength and release } \\
\text { probability }\end{array}$ & $\begin{array}{l}\text { Mauch et al. 2001; Goritz et al. } \\
2005\end{array}$ \\
\hline Thrombospondin & Negative & $\begin{array}{l}\text { Inhibits presynaptic release at glutamatergic } \\
\text { synapses }\end{array}$ & Crawford et al. 2012 \\
\hline SPARC & Negative & $\begin{array}{l}\text { Inhibits presynaptic maturation at } \\
\text { cholinergic nerve terminals }\end{array}$ & Albrecht et al. 2012 \\
\hline \multicolumn{4}{|c|}{ Postsynaptic function } \\
\hline Glypican 4,6 & Positive & $\begin{array}{l}\text { Increases synaptic AMPA receptors; induces } \\
\text { glutamatergic synapse formation }\end{array}$ & Allen et al. 2012 \\
\hline ECM & Positive & Stabilizes AMPA receptors at synapses & $\begin{array}{l}\text { Frischknecht et al. 2009; Pyka } \\
\quad \text { et al. } 2011\end{array}$ \\
\hline $\mathrm{ADNF}$ & Positive & Increases synaptic NMDA receptors & Blondel et al. 2000 \\
\hline TNF- $\alpha$ & $\begin{array}{l}\text { Positive and } \\
\text { negative }\end{array}$ & $\begin{array}{l}\text { Increases synaptic AMPA receptors; } \\
\text { decreases synaptic } \mathrm{GABA}_{\mathrm{A}} \text { receptors }\end{array}$ & $\begin{array}{l}\text { Beattie et al. 2002; Stellwagen } \\
\text { et al. 2005; Stellwagen and } \\
\text { Malenka 2006; Steinmetz } \\
\text { and Turrigiano 2010; } \\
\text { Hennekinne et al. } 2013\end{array}$ \\
\hline Thrombospondin & $\begin{array}{l}\text { Positive and } \\
\text { negative }\end{array}$ & $\begin{array}{l}\text { Increases synaptic glycine receptors; } \\
\text { decreases synaptic AMPA receptors }\end{array}$ & \\
\hline SPARC & Negative & Decreases synaptic AMPA receptors & Jones et al. 2011 \\
\hline
\end{tabular}

was examined in two different culture systems using RGC neurons: autaptic cultures, in which individual neurons are grown in isolation and synapse onto themselves, and dense cultures, in which neurons form synapses with neighboring cells. Neurons in both autaptic and dense cultures showed an increase in mEPSC frequency in response to cholesterol, but only autaptic neurons had an increase in mEPSC amplitude (Mauch et al. 2001; Christopherson et al. 2005; Goritz et al. 2005), showing the predominant way that cholesterol enhances synaptic transmission is by strengthening presynaptic function. 
W.-S. Chung et al.

As described in the section on structural synapse formation, TSPs are astrocyte-secreted factors that strongly promote structural synapse formation, but these synapses are postsynaptically silent as they do not contain AMPA glutamate receptors (AMPARs). It has now been shown that TSPs can also regulate presynaptic function by inducing a state called presynaptic muting (Crawford et al. 2012). Muting results in a reduction in the number of presynaptic terminals that release neurotransmitter, and is thought to be an adaption to changes in neuronal firing, and a protective mechanism against excitotoxicity by limiting the release of glutamate. TSP regulation of presynaptic muting is not caused by release of TSP in response to a muting challenge, as it has to be present before the challenge occurs. Rather, TSP is proposed to be a factor that is necessary during synapse development to make presynaptic terminals muting competent using a protein kinase A (PKA)dependent mechanism. SPARC, which inhibits synapse formation in response to astrocytic hevin, also has effects on presynaptic maturation (Kucukdereli et al. 2011). Treatment of autaptic cholinergic neurons with SPARC results in an enhanced presynaptic release probability and a decrease in the number of vesicles available for release, features indicative of an immature presynaptic terminal (Albrecht et al. 2012). This shows that SPARC has multiple mechanisms to decrease synaptic communication in the developing brain.

\section{Postsynaptic Function}

Glutamatergic synapses are the predominant class of excitatory synapse in the CNS, and a number of astrocyte factors have been identified that regulate glutamatergic postsynaptic strength. These include factors that increase synaptic AMPARs (glypican 4 and -6, Gpc4/6; tumor necrosis factor [TNF]- $\alpha$ ), decrease synaptic AMPARs (SPARC; TSP), stabilize surface AMPARs (chondroitin sulfate proteoglycans [CSPGs]), and increase synaptic NMDA glutamate receptors (NMDARs) (activity-dependent neurotrophic factor $[\mathrm{ADNF}]$ ) (Blondel et al. 2000; Beattie et al. 2002; Jones et al. 2011; Pyka et al. 2011; Allen et al. 2012; Hennekinne et al. 2013).

The finding that astrocyte-secreted factors are able to up-regulate the surface level of AMPARs on RGC neurons by threefold led to a biochemical study to identify the factor responsible (Allen et al. 2012). This identified Gpc4 and -6 as astrocyte-derived proteins that are necessary and sufficient to increase GluA1containing AMPARs on the surface of neurons and at synapses, but surprisingly Gpc4/6 had no effect on surface levels of GluA2/3 or GluA4 AMPARs. Recording mEPSCs showed that Gpc4 is sufficient to increase synaptic activity in neurons, but the synaptic events have a more immature phenotype than those induced by astrocytes, suggesting that additional factors are released from astrocytes that recruit GluA2/3 to synapses and induce synaptic maturation. Possible maturation factors are ECM molecules, including CSPGs. Enzymatic digestion of the ECM causes increased mobility of AMPARs on dendritic surfaces, and a faster rate of exchange between synaptic and extrasynaptic receptors, suggesting that the ECM normally stabilizes AMPARs at synaptic sites (Frischknecht et al. 2009). Astrocytes are a source of a number of ECM molecules, and the ability of astrocytes to increase synapse formation is increased when cells are cultured in the presence of enzymes to digest the ECM, but the mEPSC amplitude is decreased, suggesting that the synapses are in an immature state and astrocyte ECM molecules contribute to stabilizing mature synapses (Pyka et al. 2011). It will be exciting to determine the relative contribution of astrocytic and neuronal ECM molecules to synapse maturation.

Astrocytes potently stimulate the formation and functional maturation of inhibitory GABAergic synapses via secreted factors, but the factor that regulates $\gamma$-aminobutyric acid receptor $\left(\mathrm{GABA}_{\mathrm{A}} \mathrm{R}\right)$ synaptic recruitment is not known. The ability of astrocytes to increase postsynaptic $\mathrm{GABA}_{\mathrm{A}} \mathrm{R}$ levels requires the presence of $\mathrm{BDNF}$ and tyrosine kinase receptor $\mathrm{B}$ ( TrkB) in neurons, thus identifying the signaling pathway that astrocytes regulate to increase synaptic $\mathrm{GABA}_{\mathrm{A}}$ Rs (Elmariah et al. 2005). Interestingly, astrocyte factors that induce excita- 
tory synapse formation, such as TSP, do not induce inhibitory GABAergic synapse formation, showing that astrocytes can dictate the class of synapse that forms via the release of specific signals (Hughes et al. 2010).

Two astrocyte factors that regulate structural synapse formation and presynaptic plasticity, SPARC and TSP, also regulate postsynaptic receptor levels, showing diverse functions for these molecules in regulating synapse development. SPARC decreases synaptic accumulation of AMPARs, fitting with its function of decreasing synapse formation and presynaptic function, suggesting it is a generally inhibitory factor (Jones et al. 2011). Secretion of SPARC from astrocytes is regulated by neuronal activity, being increased when neuronal activity increases, suggesting that SPARC acts to limit neuronal overexcitation from occurring by reducing synaptic AMPAR levels. TSP has differential effects over AMPARs and glycine receptors in mature cultures of spinal cord neurons in which synapses have already formed (Hennekinne et al. 2013). TSP increases synaptic glycine receptors and decreases synaptic AMPARs, so decreasing neuronal excitability. Again, this decrease in neuronal excitability correlates with the other known functions of TSP in inducing silent synapse formation and decreasing presynaptic release, suggesting that TSP has a role in limiting neuronal excitability in mature neuronal networks.

\section{Synaptic Plasticity}

As well as having effects on developmental synapse function, astrocyte factors have been shown to contribute to synaptic plasticity in postnatal animals. Paradigms in which a role for astrocytes has been investigated include LTP and LTD, forms of plasticity that rapidly regulate synaptic strength in response to alterations in neuronal activity, and homeostatic synaptic scaling, a compensatory up-regulation of synaptic activity in response to prolonged periods of activity deprivation. SPARC KO mice show a failure to maintain LTP in hippocampal slices (although synaptic potentiation is induced), and $\mathrm{KO}$ neurons in culture do not display homeostatic scaling in response to activ- ity blockade, presumably because the $\mathrm{KO}$ already has a saturating level of AMPARs at the synapse so is no longer in a range to increase AMPARs to undergo plasticity (Jones et al. 2011). Astrocytederived TNF- $\alpha$ rapidly induces the surface insertion of GluA1-containing AMPARs (within 15 min of treatment), causing an increase in the frequency but not amplitude of mEPSCs in cultured hippocampal neurons (Beattie et al. 2002). Interestingly, TNF- $\alpha$ has the opposite effect on $\mathrm{GABA}_{\mathrm{A}} \mathrm{Rs}$, causing a decrease in the surface levels of these inhibitory receptors (Stellwagen et al. 2005). To investigate whether this differential effect of TNF- $\alpha$ on AMPA and $\mathrm{GABA}_{\mathrm{A}}$ receptors causes changes in excitatory/inhibitory balance in an intact neural circuit, recordings were made from neurons in hippocampal slices treated with TNF- $\alpha$. These cells had larger excitatory synaptic events and smaller inhibitory events, confirming that TNF- $\alpha$ is able to shift neurons toward a more excitable state. Does this ability of TNF- $\alpha$ have any implications for synaptic plasticity in the hippocampus? TNF- $\alpha$ KO mice show normal hippocampal LTP and LTD (Stellwagen and Malenka 2006). However, homeostatic synaptic scaling is absent in TNF- $\alpha$ KO hippocampus, showing TNF- $\alpha$ to be necessary for the up-regulation of AMPARs, which occurs during scaling. It has been suggested that the role of TNF- $\alpha$ in up-regulation of synaptic strength during activity blockade is not an instructive signal, but rather a permissive signal that must be present to maintain synapses in a scalable state (Steinmetz and Turrigiano 2010). The exact mechanism of how TNF- $\alpha$ induces homeostatic scaling awaits clarification, but, regardless of this, these studies all show that astrocytes have a powerful ability to regulate synaptic strength in response to alterations in neuronal activity.

\section{ASTROCYTES CONTROL SYNAPSE ELIMINATION}

Synapses are dynamic structures that can undergo rapid formation and elimination. During development of the nervous system, neurons initially generate excessive projections that make redundant synaptic connections with tar- 
W.-S. Chung et al.

get cells. Within critical time periods, these excessive synapses are eliminated, whereas the remaining inputs are further strengthened to form the mature neural circuit (Shatz 1983; Sanes and Lichtman 1999). Synapse-elimination processes have also been observed during synaptic plasticity in the adult brain (Xu et al. 2009b; Yang et al. 2009; Roberts et al. 2010). Sensory experience induces the formation of new spines along with the elimination of preexisting spines during learning and memory formation. Thus, synapse elimination is likely to be a central feature of remodeling and reorganization of our nervous system during learning.

How is synapse elimination achieved? A number of studies suggest that neuronal activity-dependent competition initiates the elimination of unwanted synapses, likely through the Hebbian rule; that is, correlated activities strengthen synapses, whereas uncorrelated activities weaken synapses (Hebb 1949; BaliceGordon and Lichtman 1994; Katz and Shatz 1996; Buffelli et al. 2003). However, the detailed mechanisms of how changes in neuronal activity transduce into the structural elimination of certain synapses are not well understood. Recently, glial cells, especially microglia and astrocytes, have been shown to mediate synapse elimination, providing a new type of neuronglia interaction and a mechanism for synapse elimination. Here, we will focus on the role of astrocytes in mediating synapse elimination in the normal developing and adult brain.

\section{Indirect Role of Astrocytes in Mediating Synapse Elimination}

In the developing mammalian visual system, RGCs from both eyes send axonal projections to their major target neurons in the dorsal lateral geniculate (dLGN) and form synaptic connections. Electrophysiology experiments have shown that initially there are more than 20 axonal connections from RGCs to dLGN neurons, which subsequently undergo substantial elimination during early postnatal stages leaving only one or two axonal connections per neuron (Chen and Regehr 2000). Microglia cells have been shown to phagocytose many of these extra synapses and mediate eye-specific segregation in the retinogeniculate system (Schafer et al. 2012). In this model, the initiating complement protein, $\mathrm{Clq}$, can opsonize unwanted synapses in the dLGN, along with C3 (Stevens et al. 2007), and these $\mathrm{Clq} / \mathrm{C} 3$-coated synapses are recognized and engulfed by microglia through C3Rmediated phagocytosis (Schafer et al. 2012). Importantly, the expression of C1q messenger RNA (mRNA) in RGCs is dependent on secreted factors from astrocytes (Stevens et al. 2007), whose identity has been recently identified as transforming growth factor- $\beta$ (TGF- $\beta$ ) (Bialas and Stevens 2013). TGF- $\beta$ is expressed by astrocytes and induces C1q expression in purified RGCs through the corresponding receptor TGFBR2. TGFBR2 is expressed by RGCs, with the highest level at P5, and its expression sharply decreases by $\mathrm{P} 15$, thus generating a critical time window for astrocytes to induce $\mathrm{C} 1 \mathrm{q}$ expression. Genetic and pharmacological manipulations to block TGFBR2 show that C1q expression in RGCs induced by astrocytic TGF- $\beta$ is critical for phagocytic functions of microglia (Bialas and Stevens 2013). Interestingly, Clq mRNA is also highly expressed by microglial cells, but its expression is not regulated by TGF- $\beta$. In contrast to the retina, in which C1q expression in RGCs decline sharply by $\mathrm{P} 15, \mathrm{Clq}$ is continuously being expressed by microglial cells in the brain and its protein level dramatically accumulates in the normal aging brain (Stephan et al. 2013). Thus, these data reveal the indirect role of astrocytes in initiating C1q expression in RGCs and mediating microglial-dependent synapse elimination (Fig. 4A).

\section{Direct Role of Astrocytes in Mediating Synapse Elimination}

Through gene expression analysis, astrocytes were found to express a plethora of genes that have been implicated in engulfment and phagocytosis (Cahoy et al. 2008). These phagocytic genes can be categorized into three main pathways, which begin in serial, but then converge into common downstream pathways in ways that are still poorly understood. The first pathway includes the proteins CrKII, DOCK180, ELMO, and Rac1, which control rearrangement 
Synapse Formation, Function, and Elimination
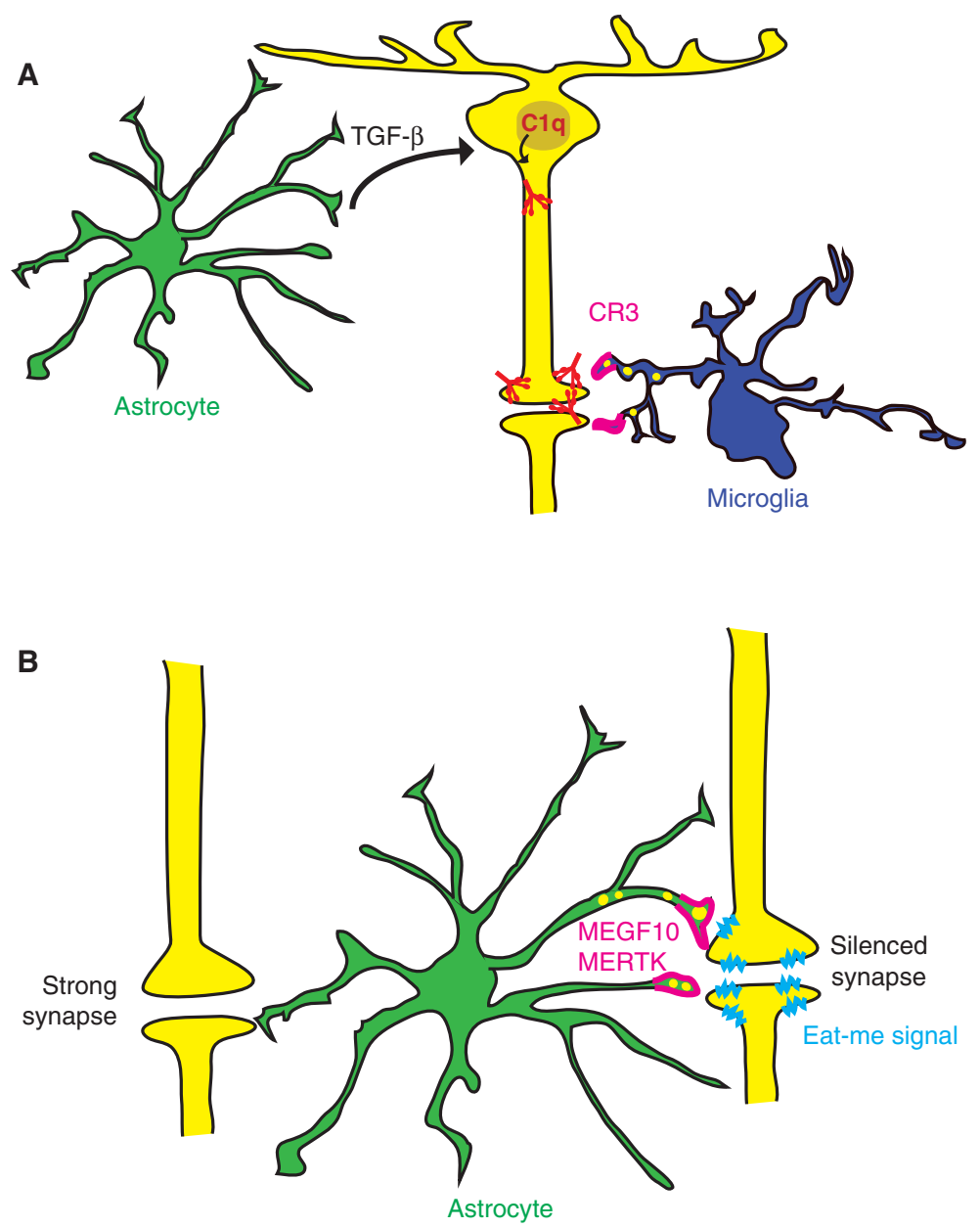

Figure 4. Astrocytes mediate synapse elimination through indirect $(A)$, and direct $(B)$ mechanisms. $(A)$ Astrocytes (green) induce C1q expression (red) in RGCs (yellow) through TGF- $\beta$ signaling. C1q-labeled synapses can be recognized by complement component-3 receptors (C3R, magenta) in microglia (dark blue) and eliminated through complement-dependent phagocytosis. $(B)$ Astrocytes (green) directly eliminate synapses by recognizing "eat-me signals" (light blue) presented in the silent synapses and phagocytosing them through MEGF10 and MERTK phagocytic pathways (magenta).

of the actin cytoskeleton which is required for membrane dynamics of phagocytes when surrounding cellular debris (Kinchen et al. 2005). Bail has been identified as a phagocytic receptor that is expressed by astrocytes, and acts upstream of these components (Park et al. 2007). The second pathway includes the TAM receptors, TYRO3, AXL, and MERTK (Lemke 2013), which in part work with the integrin pathway to regulate CrKII/DOCK180/ELMO/Rac1 modules (Wu et al. 2005). The last pathway consists of
MEGF10 (an ortholog of Drosophila Draper and C. elegans CED-1), GULP (an ortholog of Drosophila dCed-6 and C. elegans CED-6), and ABCA1 (ATP-binding cassette, subfamily A member 1), and participates in cellular debris recognition and engulfment (Zhou et al. 2001; MacDonald et al. 2006; Yu et al. 2008).

The phagocytic capacity of astrocytes has been shown previously in in vitro culture (Park et al. 2007; Loov et al. 2012) and in vivo models of injury (al-Ali and al-Hussain 1996; 
W.-S. Chung et al.

Bechmann and Nitsch 1997), glioma (Lantos 1974), and developmental neuronal/axonal death (Berbel and Innocenti 1988; Mazlo et al. 2004). More recently, evidence of a phagocytic capacity of in vivo astrocytes came from a study showing axonal organelle engulfment by adult astrocytes in the optic nerve head (Nguyen et al. 2011). Astrocytes in the optic nerve head express Mac-2 (Lgals3), a bridging molecule that mediates the binding of target debris with phagocytic receptors (Caberoy et al. 2012), and astrocytes continuously phagocytose axonal organelles in the noninjured optic nerve (Nguyen et al. 2011). A recent follow-up study has revealed that the axonal evulsions contain axoplasmic components including mitochondria, suggesting large amounts of neuronal mitochondria are degraded by astrocytes within the optic nerve head (Davis et al. 2014). Although further studies are required to determine the functional requirement of Mac-2 for axonal phagocytosis by astrocytes, and its physiological role in the optic nerve head, this study shows that astrocytes are continuously phagocytic in normal adult stages and suggests astrocytes may play important roles in maintaining homeostasis of the nervous system through clearing damaged organelles and debris.

The role of phagocytic activity of astrocytes in directly mediating synapse elimination has been recently discovered (Fig. 4B) (Chung et al. 2013). Using an in vitro engulfment assay, as well as in vivo analysis in the developing retinogeniculate system, astrocytes were found to eliminate synapses and neural debris efficiently. Astrocyte-mediated synapse elimination is dependent on two phagocytic receptors, MEGF10 and MERTK. Astrocytes deficient in either one of these phagocytic receptors show a 50\% reduction in their relative phagocytic capacity, and astrocytes deficient in both receptors show greater defects, suggesting that MEGF10 and MERTK work in parallel to mediate synapse-elimination processes. Importantly, in mice deficient in both MEGF10 and MERTK, developing RGCs fail to normally refine their connections and retain excess functional synapses with neurons in the dLGN, thus providing evidence that astrocytes actively participate in synapse elimination rather than simply cleaning up already dead synapses. Previous studies have shown that eye-specific segregation in the dLGN is regulated by spontaneous retinal waves, which are bursts of action potentials that spread across large regions of the RGC layer and occur before eye opening (Penn et al. 1998; Huberman et al. 2002; Stellwagen and Shatz 2002; Feller 2009). Interestingly, synapse-elimination processes by astrocytes are strongly dependent on neural activity, because blocking spontaneous retinal waves in both eyes significantly reduces astrocyte-mediated phagocytosis of bilateral synaptic inputs, whereas selective blocking of activity in only one eye induces preferential engulfment of the silenced synapses by astrocytes (Chung et al. 2013). Therefore, astrocytes actively contribute to neural activity-dependent synapse pruning and elimination that mediates neural circuit refinement by phagocytosing unwanted synapses through MEGF10 and MERTK pathways.

The expression of phagocytic machineries including MEGF10 and MERTK in astrocytes persists into adulthood, raising the question of whether astrocytes continuously engulf synapses in the adult brain. By examining the somatosensory cortex from 1- and 4-mo-old mouse brains, astrocytes were shown to actively engulf both excitatory and inhibitory synapses. Drosophila glia, which resemble mammalian astrocytes, also phagocytose synapses during metamorphosis using Draper (an ortholog of Megf10) and $\mathrm{Crk} / \mathrm{Mbc} / \mathrm{dCed}-12$ (orthologs of CrKII/ DOCK1/ELMO) signaling pathways, indicating that the phagocytic function of astrocytes is evolutionarily conserved (Tasdemir-Yilmaz and Freeman 2014).

Thus, astrocytes share with microglia the ability to actively engulf and eliminate synapses in response to neural activity during development and adult stages, but synapse engulfment by astrocytes uses distinct phagocytic pathways from those used by microglia (Fig. 4B). Because astrocytes normally ensheath synapses and are in the perfect position to monitor synaptic activity, this newly discovered phagocytic function of astrocytes in eliminating synapses suggests that the synaptic architecture 
may be constantly remodeled by astrocytes in response to experience.

\section{CONCLUDING REMARKS}

Here we have reviewed some of the advances in our knowledge of astrocyte-synapse interactions, which have provided new insights into the important and vast roles of astrocytes in the formation, function, and elimination of synapses. We focused particularly on astrocytes from mammalian systems. Interestingly, many of the cellular and molecular mechanisms used by mammalian astrocytes to achieve the correct synaptic connectivity are evolutionarily conserved, further indicating the importance of astrocyte-synapse interactions for a functional nervous system. Many important questions still remain to be answered. How do astrocyte-derived factors facilitate synapse formation, alter synaptic function, and accomplish synaptic pruning with high precision? Do astrocytes regulate critical periods of plasticity? Do astrocytes participate in experience-dependent modulation of neuronal circuit function? Importantly, the pathogenesis of many neurological disorders, such as amyotrophic lateral sclerosis (ALS), Rett syndrome, fragile-X syndrome, and psychiatric disorders, have been tightly linked to astrocyte dysfunction (Sloan and Barres 2014). Therefore, answering these questions will not only provide the necessary in-depth understanding of the nervous system but also may present important clues for overcoming neurological pathologies.

\section{REFERENCES}

${ }^{*}$ Reference is also in this collection.

al-Ali SY, al-Hussain SM. 1996. An ultrastructural study of the phagocytic activity of astrocytes in adult rat brain. $J$ Anat 188: 257-262.

Albrecht D, Lopez-Murcia FJ, Perez-Gonzalez AP, Lichtner G, Solsona C, Llobet A. 2012. SPARC prevents maturation of cholinergic presynaptic terminals. Mol Cell Neurosci 49: 364-374.

Allen NJ, Bennett ML, Foo LC, Wang GX, Chakraborty C, Smith SJ, Barres BA. 2012. Astrocyte glypicans 4 and 6 promote formation of excitatory synapses via GluA1 AMPA receptors. Nature 486: 410-414.
Araque A, Parpura V, Sanzgiri RP, Haydon PG. 1999. Tripartite synapses: Glia, the unacknowledged partner. Trends Neurosci 22: 208-215.

Bacaj T, Tevlin M, Lu Y, Shaham S. 2008. Glia are essential for sensory organ function in C. elegans. Science 322: 744747.

Balice-Gordon RJ, Lichtman JW. 1994. Long-term synapse loss induced by focal blockade of postsynaptic receptors. Nature 372: 519-524.

Banker GA. 1980. Trophic interactions between astroglial cells and hippocampal neurons in culture. Science 209: 809-810.

Barker AJ, Koch SM, Reed J, Barres BA, Ullian EM. 2008. Developmental control of synaptic receptivity. J Neurosci 28: $8150-8160$.

Beattie EC, Stellwagen D, Morishita W, Bresnahan JC, Ha BK, Von Zastrow M, Beattie MS, Malenka RC. 2002. Control of synaptic strength by glial TNF- $\alpha$. Science 295: 2282-2285.

Bechmann I, Nitsch R. 1997. Astrocytes and microglial cells incorporate degenerating fibers following entorhinal lesion: A light, confocal, and electron microscopical study using a phagocytosis-dependent labeling technique. Glia 20: $145-154$.

Benner EJ, Luciano D, Jo R, Abdi K, Paez-Gonzalez P, Sheng H, Warner DS, Liu C, Eroglu C, Kuo CT. 2013. Protective astrogenesis from the SVZ niche after injury is controlled by Notch modulator Thbs4. Nature 497: 369-373.

Berbel P, Innocenti GM. 1988. The development of the corpus callosum in cats: A light- and electron-microscopic study. J Comp Neurol 276: 132-156.

Bialas AR, Stevens B. 2013. TGF- $\beta$ signaling regulates neuronal C1q expression and developmental synaptic refinement. Nat Neurosci 16: 1773-1782.

Blondel O, Collin C, McCarran WJ, Zhu S, Zamostiano R, Gozes I, Brenneman DE, McKay RDG. 2000. A glia-derived signal regulating neuronal differentiation. J Neurosci 20: $8012-8020$.

Boroujerdi A, Zeng J, Sharp K, Kim D, Steward O, Luo ZD. 2011. Calcium channel $\alpha-2-\delta-1$ protein upregulation in dorsal spinal cord mediates spinal cord injury-induced neuropathic pain states. Pain 152: 649-655.

Buard I, Steinmetz CC, Claudepierre T, Pfrieger FW. 2010. Glial cells promote dendrite formation and the reception of synaptic input in Purkinje cells from postnatal mice. Glia 58: 538-545.

Buffelli M, Burgess RW, Feng G, Lobe CG, Lichtman JW, Sanes JR. 2003. Genetic evidence that relative synaptic efficacy biases the outcome of synaptic competition. $\mathrm{Na}$ ture 424: 430-434.

Bushong EA, Martone ME, Jones YZ, Ellisman MH. 2002. Protoplasmic astrocytes in CA1 stratum radiatum occupy separate anatomical domains. J Neurosci 22: 183-192.

Caberoy NB, Alvarado G, Bigcas JL, Li W. 2012. Galectin-3 is a new MerTK-specific eat-me signal. J Cell Physiol 227: 401-407.

Cahoy JD, Emery B, Kaushal A, Foo LC, Zamanian JL, Christopherson KS, Xing Y, Lubischer JL, Krieg PA, Krupenko SA, et al. 2008. A transcriptome database for astrocytes, neurons, and oligodendrocytes: A new resource 
W.-S. Chung et al.

for understanding brain development and function. $J$ Neurosci 28: 264-278.

Cao G, Ko C-P. 2007. Schwann cell-derived factors modulate synaptic activities at developing neuromuscular synapses. J Neurosci 27: 6712-6722.

Carmona MA, Murai KK, Wang L, Roberts AJ, Pasquale EB. 2009. Glial ephrin-A3 regulates hippocampal dendritic spine morphology and glutamate transport. Proc Natl Acad Sci 106: 12524-12529.

Chen C, Regehr WG. 2000. Developmental remodeling of the retinogeniculate synapse. Neuron 28: 955-966.

Christopherson K, Ullian E, Stokes C, Mullowney C, Hell J, Agah A, Lawler J, Mosher D, Bornstein P, Barres B. 2005. Thrombospondins are astrocyte-secreted proteins that promote CNS synaptogenesis. Cell 120: 421-433.

Chung WS, Clarke LE, Wang GX, Stafford BK, Sher A, Chakraborty C, Joung J, Foo LC, Thompson A, Chen C, et al. 2013. Astrocytes mediate synapse elimination through MEGF10 and MERTK pathways. Nature 504: 394-400.

Crawford DC, Jiang X, Taylor A, Mennerick S. 2012. Astrocyte-derived thrombospondins mediate the development of hippocampal presynaptic plasticity in vitro. J Neurosci 32: $13100-13110$.

Cuevas ME, Carrasco MA, Fuentes Y, Castro P, Nualart F, Roa J, Aguayo LG. 2005. The presence of glia stimulates the appearance of glycinergic synaptic transmission in spinal cord neurons. Mol Cell Neurosci 28: 770-778.

Davis CH, Kim KY, Bushong EA, Mills EA, Boassa D, Shih T, Kinebuchi M, Phan S, Zhou Y, Bihlmeyer NA, et al. 2014. Transcellular degradation of axonal mitochondria. Proc Natl Acad Sci 111: 9633-9638.

Diniz LP, Almeida JC, Tortelli V, Vargas Lopes C, Setti-Perdigao P, Stipursky J, Kahn SA, Romao LF, de Miranda J Alves-Leon SV, et al. 2012. Astrocyte-induced synaptogenesis is mediated by transforming growth factor beta signaling through modulation of D-serine levels in cerebral cortex neurons. J Biol Chem 287: 41432-41445.

Distler C, Dreher Z, Stone J. 1991. Contact spacing among astrocytes in the central nervous system: An hypothesis of their structural role. Glia 4: 484-494.

Elmariah SB, Oh EJ, Hughes EG, Balice-Gordon RJ. 2005. Astrocytes regulate inhibitory synapse formation via Trkmediated modulation of postsynaptic $\mathrm{GABA}_{\mathrm{A}}$ receptors. J Neurosci 25: 3638-3650.

Eroglu C. 2009. The role of astrocyte-secreted matricellular proteins in central nervous system development and function. J Cell Commun Signal 3: 167-176.

Eroglu C, Allen NJ, Susman MW, O'Rourke NA, Park CY, Özkan E, Chakraborty C, Mulinyawe SB, Annis DS, Huberman AD. 2009. Gabapentin receptor $\alpha 2 \delta-1$ is a neuronal thrombospondin receptor responsible for excitatory CNS synaptogenesis. Cell 139: 380-392.

Feller MB. 2009. Retinal waves are likely to instruct the formation of eye-specific retinogeniculate projections. $\mathrm{Neu}$ ral Dev 4: 24.

Feng Z, Ko C-P. 2008. Schwann cells promote synaptogenesis at the neuromuscular junction via transforming growth factor- $\beta 1$. J Neurosci 28: 9599-9609.

Filosa A, Paixao S, Honsek SD, Carmona MA, Becker L, Feddersen B, Gaitanos L, Rudhard Y, Schoepfer R, Klopstock T, et al. 2009. Neuron-glia communication via
EphA4/ephrin-A3 modulates LTP through glial glutamate transport. Nat Neurosci 12: 1285-1292.

Frischknecht R, Heine M, Perrais D, Seidenbecher CI, Choquet D, Gundelfinger ED. 2009. Brain extracellular matrix affects AMPA receptor lateral mobility and shortterm synaptic plasticity. Nat Neurosci 12: 897-904.

Fuentes-Medel Y, Ashley J, Barria R, Maloney R, Freeman M, Budnik V. 2012. Integration of a retrograde signal during synapse formation by glia-secreted TGF- $\beta$ ligand. Curr Biol 22: 1831-1838.

Garcia O, Torres M, Helguera P, Coskun P, Busciglio J. 2010. A role for thrombospondin-1 deficits in astrocyte-mediated spine and synaptic pathology in Down's syndrome. PLOS ONE 5: e14200.

Garrett AM, Weiner JA. 2009. Control of CNS synapse development by $\gamma$-protocadherin-mediated astrocyte-neuron contact. J Neurosci 29: 11723-11731.

Genoud C, Quairiaux C, Steiner P, Hirling H, Welker E, Knott GW. 2006. Plasticity of astrocytic coverage and glutamate transporter expression in adult mouse cortex. PLoS Biol 4: e343.

Gómez-Casati ME, Murtie JC, Rio C, Stankovic K, Liberman MC, Corfas G. 2010. Nonneuronal cells regulate synapse formation in the vestibular sensory epithelium via erbB-dependent BDNF expression. Proc Natl Acad Sci 107: 17005-17010.

Goritz C, Mauch DH, Pfrieger FW. 2005. Multiple mechanisms mediate cholesterol-induced synaptogenesis in a CNS neuron. Mol Cell Neurosci 29: 190-201.

Grass D, Pawlowski PG, Hirrlinger J, Papadopoulos N, Richter DW, Kirchhoff F, Hulsmann S. 2004. Diversity of functional astroglial properties in the respiratory network. $J$ Neurosci 24: 1358-1365.

Grosche J, Matyash V, Moller T, Verkhratsky A, Reichenbach A, Kettenmann H. 1999. Microdomains for neuron-glia interaction: Parallel fiber signaling to Bergmann glial cells. Nat Neurosci 2: 139-143.

Haber M, Zhou L, Murai KK. 2006. Cooperative astrocyte and dendritic spine dynamics at hippocampal excitatory synapses. J Neurosci 26: 8881-8891.

Halassa MM, Fellin T, Takano H, Dong JH, Haydon PG. 2007. Synaptic islands defined by the territory of a single astrocyte. J Neurosci 27: 6473-6477.

Hama H, Hara C, Yamaguchi K, Miyawaki A. 2004. PKC signaling mediates global enhancement of excitatory synaptogenesis in neurons triggered by local contact with astrocytes. Neuron 41: 405-415.

Hartley RS, Margulis M, Fishman PS, Lee VMY, Tang C-M. 1999. Functional synapses are formed between human NTera2 (NT2N, hNT) neurons grown on astrocytes. $J$ Comp Neurol 407: 1-10.

* Haydon PG, Nedergaard M. 2015. How do astrocytes participate in neural plasticity? Cold Spring Harb Perspect Biol doi: 10.1101/cshperspect.a020438.

Hebb DO. 1949. The organization of behavior: A neuropsychological theory. Wiley, New York.

Hennekinne L, Colasse S, Triller A, Renner M. 2013. Differential control of thrombospondin over synaptic glycine and AMPA receptors in spinal cord neurons. J Neurosci 33: $11432-11439$. 
Hu R, Cai WQ, Wu XG, Yang Z. 2007. Astrocyte-derived estrogen enhances synapse formation and synaptic transmission between cultured neonatal rat cortical neurons. Neuroscience 144: 1229-1240.

Huberman AD, Stellwagen D, Chapman B. 2002. Decoupling eye-specific segregation from lamination in the lateral geniculate nucleus. J Neurosci 22: 9419-9429.

Hughes EG, Elmariah SB, Balice-Gordon RJ. 2009. Astrocyte secreted proteins selectively increase hippocampal GABAergic axon length, branching, and synaptogenesis. Mol Cell Neurosci 43: 136-145.

Johnson MA, Weick JP, Pearce RA, Zhang S-C. 2007. Functional neural development from human embryonic stem cells: Accelerated synaptic activity via astrocyte coculture. I Neurosci 27: 3069-3077.

Johnston IG, Paladino T, Gurd JW, Brown IR. 1990. Molecular cloning of SC1: A putative brain extracellular matrix glycoprotein showing partial similarity to osteonectin/ BM40/SPARC. Neuron 4: 165-176.

Jones TA, Greenough WT. 1996. Ultrastructural evidence for increased contact between astrocytes and synapses in rats reared in a complex environment. Neurobiol Learn Mem 65: $48-56$.

Jones EV, Bernardinelli Y, Tse YC, Chierzi S, Wong TP, Murai KK. 2011. Astrocytes control glutamate receptor levels at developing synapses through SPARC $-\beta$-integrin interactions. J Neurosci 31: 4154-4165.

Katz LC, Shatz CJ. 1996. Synaptic activity and the construction of cortical circuits. Science 274: 1133-1138.

Kim DS, Li KW, Boroujerdi A, Peter Yu Y, Zhou CY, Deng P, Park J, Zhang X, Lee J, Corpe M, et al. 2012. Thrombospondin-4 contributes to spinal sensitization and neuropathic pain states. J Neurosci 32: 8977-8987.

Kinchen JM, Cabello J, Klingele D, Wong K, Feichtinger R, Schnabel H, Schnabel R, Hengartner MO. 2005. Two pathways converge at CED-10 to mediate actin rearrangement and corpse removal in C. elegans. Nature 434: 93-99.

* Ko C-P, Robitaille R. 2015. Perisynaptic Schwann cells at the neuromuscular synapse: Adaptable, multitasking glial cells. Cold Spring Harb Perspect Biol doi: 10.1101/ cshperspect.a020503.

Kucukdereli H, Allen NJ, Lee AT, Feng A, Ozlu MI, Conatser LM, Chakraborty C, Workman G, Weaver M, Sage EH, et al. 2011. Control of excitatory CNS synaptogenesis by astrocyte-secreted proteins Hevin and SPARC. Proc Natl Acad Sci 108: E440-E449.

Lantos PL. 1974. An electron microscope study of reacting astrocytes in gliomas induced by $\mathrm{N}$-ethyl- $\mathrm{N}$-nitrosourea in rats. Acta Neuropathol 30: 175-181.

Lehre KP, Rusakov DA. 2002. Asymmetry of glia near central synapses favors presynaptically directed glutamate escape. Biophys J 83: 125-134.

Lemke G. 2013. Biology of the TAM receptors. Cold Spring Harb Perspect Biol 5: a009076.

Li Y-X, Schaffner AE, Barker JL. 1999. Astrocytes regulate the developmental appearance of GABAergic and glutamatergic postsynaptic currents in cultured embryonic rat spinal neurons. Eur J Neurosci 11: 2537-2551.

Li H, Graber KD, Jin S, McDonald W, Barres BA, Prince DA. 2012a. Gabapentin decreases epileptiform discharges in a
Synapse Formation, Function, and Elimination

chronic model of neocortical trauma. Neurobiol Dis 48: 429-438.

Li X, Newbern JM, Wu Y, Morgan-Smith M, Zhong J, Charron J, Snider WD. 2012b. MEK is a key regulator of gliogenesis in the developing brain. Neuron 75: 1035-1050.

Liauw J, Hoang S, Choi M, Eroglu C, Choi M, Sun GH, Percy M, Wildman-Tobriner B, Bliss T, Guzman RG, et al. 2008. Thrombospondins 1 and 2 are necessary for synaptic plasticity and functional recovery after stroke. J Cereb Blood Flow Metab 28: 1722-1732.

Liu Q-Y, Schaffner AE, Li Y-X, Dunlap V, Barker JL. 1996. Upregulation of $\mathrm{GABA}_{\mathrm{A}}$ current by astrocytes in cultured embryonic rat hippocampal neurons. J Neurosci 16: 2912-2923.

Lively S, Brown IR. 2008. The extracellular matrix protein SC1/hevin localizes to excitatory synapses following status epilepticus in the rat lithium-pilocarpine seizure model. J Neurosci Res 86: 2895-2905.

Loov C, Hillered L, Ebendal T, Erlandsson A. 2012. Engulfing astrocytes protect neurons from contact-induced apoptosis following injury. PloS ONE 7: e33090.

MacDonald JM, Beach MG, Porpiglia E, Sheehan AE, Watts RJ, Freeman MR. 2006. The Drosophila cell corpse engulfment receptor Draper mediates glial clearance of severed axons. Neuron 50: 869-881.

Mauch DH, Nagler K, Schumacher S, Goritz C, Muller EC, Otto A, Pfrieger FW. 2001. CNS synaptogenesis promoted by glia-derived cholesterol. Science 294: 1354-1357.

Mazlo M, Gasz B, Szigeti A, Zsombok A, Gallyas F. 2004 Debris of "dark" (compacted) neurones are removed from an otherwise undamaged environment mainly by astrocytes via blood vessels. J Neurocytol 33: 557-567.

McKellar CE, Shatz CJ. 2009. Synaptogenesis in purified cortical subplate neurons. Cereb Cortex 19: 1723-1737.

Meyer-Franke A, Kaplan MR, Pfrieger FW, Barres BA. 1995. Characterization of the signaling interactions that promote the survival and growth of developing retinal ganglion cells in culture. Neuron 15: 805-819.

Murai KK, Nguyen LN, Irie F, Yamaguchi Y, Pasquale EB. 2003. Control of hippocampal dendritic spine morphology through ephrin-A3/EphA4 signaling. Nat Neurosci 6: 153- 160 .

Murakoshi H, Yasuda R. 2012. Postsynaptic signaling during plasticity of dendritic spines. Trends Neurosci 35: 135143.

Nguyen JV, Soto I, Kim KY, Bushong EA, Oglesby E, Valiente-Soriano FJ, Yang Z, Davis CH, Bedont JL, Son JL, et al. 2011. Myelination transition zone astrocytes are constitutively phagocytic and have synuclein dependent reactivity in glaucoma. Proc Natl Acad Sci 108: 11761181.

Oberheim NA, Takano T, Han X, He W, Lin JH, Wang F, Xu Q, Wyatt JD, Pilcher W, Ojemann JG, et al. 2009. Uniquely hominid features of adult human astrocytes. J Neurosci 29: 3276-3287.

Ogata K, Kosaka T. 2002. Structural and quantitative analysis of astrocytes in the mouse hippocampus. Neuroscience 113: 221-233.

Park D, Tosello-Trampont AC, Elliott MR, Lu M, Haney LB, Ma Z, Klibanov AL, Mandell JW, Ravichandran KS. 2007. BAI1 is an engulfment receptor for apoptotic cells up- 
W.-S. Chung et al.

stream of the ELMO/Dock180/Rac module. Nature 450: $430-434$.

Penn AA, Riquelme PA, Feller MB, Shatz CJ. 1998. Competition in retinogeniculate patterning driven by spontaneous activity. Science 279: 2108-2112.

Pfrieger FW, Barres BA. 1997. Synaptic efficacy enhanced by glial cells in vitro. Science 277: 1684-1687.

Pyka M, Wetzel C, Aguado A, Geissler M, Hatt H, Faissner A. 2011. Chondroitin sulfate proteoglycans regulate astrocyte-dependent synaptogenesis and modulate synaptic activity in primary embryonic hippocampal neurons Eur J Neurosci 33: 2187-2202.

Reddy LV, Koirala S, Sugiura Y, Herrera AA, Ko C-P. 2003. Glial cells maintain synaptic structure and function and promote development of the neuromuscular junction in vivo. Neuron 40: 563-580.

Risher WC, Eroglu C. 2012. Thrombospondins as key regulators of synaptogenesis in the central nervous system. Matrix Biol 31: 170-177.

Roberts TF, Tschida KA, Klein ME, Mooney R. 2010. Rapid spine stabilization and synaptic enhancement at the onset of behavioural learning. Nature 463: 948-952.

Rusakov DA, Lehre KP. 2002. Perisynaptic asymmetry of glia: New insights into glutamate signalling. Trends $\mathrm{Neu}$ rosci 25: $492-494$.

Sanes JR, Lichtman JW. 1999. Development of the vertebrate neuromuscular junction. Annu Rev Neurosci 22: 389442.

Schafer DP, Lehrman EK, Kautzman AG, Koyama R, Mardinly AR, Yamasaki R, Ransohoff RM, Greenberg ME, Barres BA, Stevens B. 2012. Microglia sculpt postnatal neural circuits in an activity and complement-dependent manner. Neuron 74: 691-705.

* Shaham S. 2015. Glial development and function in the nervous system of C. elegans. Cold Spring Harb Perspect Biol doi: 10.1101/cshperspect.a020578.

Shatz CJ. 1983. The prenatal development of the cat's retinogeniculate pathway. J Neurosci 3: 482-499.

Sloan SA, Barres BA. 2014. Mechanisms of astrocyte development and their contributions to neurodevelopmental disorders. Curr Opin Neurobiol 27C: 75-81.

Song H-J, Stevens CF, Gage FH. 2002. Neural stem cells from adult hippocampus develop essential properties of functional CNS neurons. Nat Neurosci 5: 438-445.

Spacek J. 1985. Three-dimensional analysis of dendritic spines: III. Glial sheath. Anat Embryol (Berl) 171: 245252.

Steinmetz CC, Turrigiano GG. 2010. Tumor necrosis factor$\alpha$ signaling maintains the ability of cortical synapses to express synaptic scaling. J Neurosci 30: 14685-14690.

Stellwagen D, Malenka RC. 2006. Synaptic scaling mediated by glial TNF- $\alpha$. Nature 440: 1054-1059.
Stellwagen D, Shatz CJ. 2002. An instructive role for retinal waves in the development of retinogeniculate connectivity. Neuron 33: 357-367.

Stellwagen D, Beattie EC, Seo JY, Malenka RC. 2005. Differential regulation of AMPA receptor and GABA receptor trafficking by tumor necrosis factor- $\alpha$. J Neurosci 25: 3219-3228.

Stephan AH, Madison DV, Mateos JM, Fraser DA, Lovelett EA, Coutellier L, Kim L, Tsai HH, Huang EJ, Rowitch $\mathrm{DH}$, et al. 2013. A dramatic increase of C1q protein in the CNS during normal aging. J Neurosci 33: 1346013474.

Stevens B, Allen NJ, Vazquez LE, Howell GR, Christopherson KS, Nouri N, Micheva KD, Mehalow AK, Huberman AD, Stafford B, et al. 2007. The classical complement cascade mediates CNS synapse elimination. Cell 131: 1164-1178.

Tasdemir-Yilmaz OE, Freeman MR. 2014. Astrocytes engage unique molecular programs to engulf pruned neuronal debris from distinct subsets of neurons. Genes Dev 28: 20-33.

Ullian EM, Sapperstein SK, Christopherson KS, Barres BA. 2001. Control of synapse number by glia. Science 291: 657-661.

Ullian EM, Harris BT, Wu A, Chan JR, Barres BA. 2004. Schwann cells and astrocytes induce synapse formation by spinal motor neurons in culture. Mol Cell Neurosci 25: 241-251.

Ventura R, Harris KM. 1999. Three-dimensional relationships between hippocampal synapses and astrocytes. J Neurosci 19: 6897-6906.

Wittkowski W, Brinkmann H. 1974. Changes of extent of neuro-vascular contacts and number of neuro-glial synaptoid contacts in the pituitary posterior lobe of dehydrated rats. Anat Embryol (Berl) 146: 157-165.

Wu Y, Singh S, Georgescu MM, Birge RB. 2005. A role for Mer tyrosine kinase in $\alpha v \beta 5$ integrin-mediated phagocytosis of apoptotic cells. J Cell Sci 118: 539-553.

Xu J, Xiao N, Xia J. 2009a. Thrombospondin 1 accelerates synaptogenesis in hippocampal neurons through neuroligin 1. Nat Neurosci 13: 22-24.

Xu T, Yu X, Perlik AJ, Tobin WF, Zweig JA, Tennant K, Jones T, Zuo Y. 2009b. Rapid formation and selective stabilization of synapses for enduring motor memories. Nature 462: 915-919.

Yang G, Pan F, Gan WB. 2009. Stably maintained dendritic spines are associated with lifelong memories. Nature 462: 920-924.

Yu X, Lu N, Zhou Z. 2008. Phagocytic receptor CED-1 initiates a signaling pathway for degrading engulfed apoptotic cells. PLoS Biol 6: e61.

Zhou Z, Hartwieg E, Horvitz HR. 2001. CED-1 is a transmembrane receptor that mediates cell corpse engulfment in C. elegans. Cell 104: 43-56. 


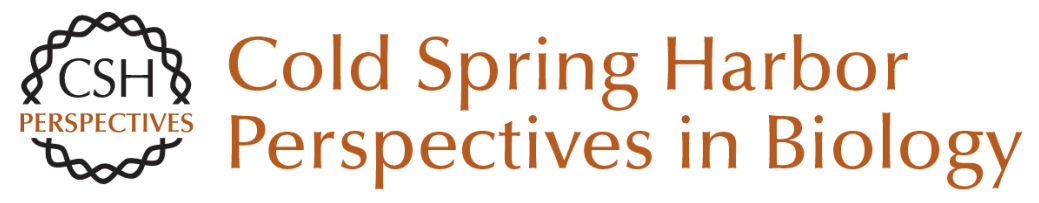

\title{
Astrocytes Control Synapse Formation, Function, and Elimination
}

\author{
Won-Suk Chung, Nicola J. Allen and Cagla Eroglu \\ Cold Spring Harb Perspect Biol 2015; doi: 10.1101/cshperspect.a020370 originally published online \\ February 6, 2015
}

\section{Subject Collection Glia}

The Nodes of Ranvier: Molecular Assembly and Maintenance

Matthew N. Rasband and Elior Peles

Microglia in Health and Disease

Richard M. Ransohoff and Joseph El Khoury

The Astrocyte: Powerhouse and Recycling Center Bruno Weber and L. Felipe Barros

Microglia Function in Central Nervous System

Development and Plasticity

Dorothy P. Schafer and Beth Stevens

Transcriptional and Epigenetic Regulation of Oligodendrocyte Development and Myelination in the Central Nervous System

Ben Emery and Q. Richard Lu

Origin of Microglia: Current Concepts and Past

Controversies

Florent Ginhoux and Marco Prinz

Glia Disease and Repair--Remyelination

Robin J.M. Franklin and Steven A. Goldman

Astrocytes in Neurodegenerative Disease

Hemali Phatnani and Tom Maniatis
Oligodendrocyte Development and Plasticity Dwight E. Bergles and William D. Richardson

Oligodendrocytes: Myelination and Axonal

Support Mikael Simons and Klaus-Armin Nave

Drosophila Central Nervous System Glia Marc R. Freeman

Perisynaptic Schwann Cells at the Neuromuscular

Synapse: Adaptable, Multitasking Glial Cells Chien-Ping Ko and Richard Robitaille

Astrocytes Control Synapse Formation, Function, and Elimination Won-Suk Chung, Nicola J. Allen and Cagla Eroglu

Schwann Cell Myelination James L. Salzer

Schwann Cells: Development and Role in Nerve Repair

Kristján R. Jessen, Rhona Mirsky and Alison C. Lloyd

Perineurial Glia

Sarah Kucenas

For additional articles in this collection, see http://cshperspectives.cshlp.org/cgi/collection/

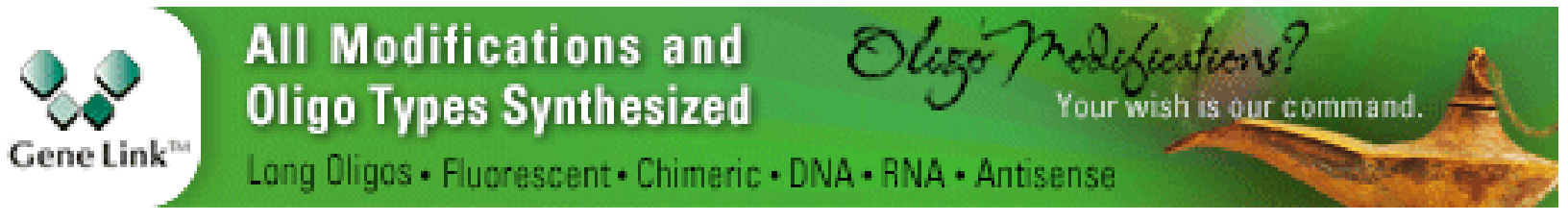

